\title{
USO DE BIOMASSA DE ALGAS PARA A PELETIZAÇÃO DE SEMENTES DE Bowdichia virgilioides Kunth ${ }^{1}$
}

\author{
Graziela Cristina Montanhim², Renata Natsumi Haneda ${ }^{3}$, Ana Teresa Lombardi ${ }^{3}$ e Maria Inês Salgueiro \\ Lima $^{3}$
}

\begin{abstract}
RESUMO - Microalgas são consideradas organismos promissores com aplicações em diversas áreas, entre elas para a fixação de $\mathrm{CO}_{2}$, indústria alimentícia, cosmética e farmacêutica. A industrialização na produção desses organismos levará à geração de resíduos, cuja utilização é vista como contribuinte na redução de custos de produção. Nesta pesquisa, propôs-se o uso de microalgas como material cimentante para peletização de sementes de Bowdichia virgilioides Kunth, espécie nativa do Cerrado brasileiro. Biomassa das microalgas Selenastrum capricornutum e Chlorella sorokiniana foram obtidas a partir de cultivos semicontrolados em casa de vegetação. Nas microalgas, foi determinada a concentração de clorofila a, proteínas, carboidratos e lipídios totais, e a biomassa para peletização foi obtida com as células em fase estacionária de crescimento. Com relação às sementes, os tratamentos consistiram de semente nua, semente com gesso agrícola, semente com gesso agrícola e $S$. capricornutum ou com C. sorokiniana. Nessas, analisaram-se a emergência e desenvolvimento das plântulas e ocorrência de nódulos fixadores de nitrogênio. Os resultados indicaram que sementes com gesso e C. sorokiniana apresentaram porcentagem de emergência $(76 \%)$ estatisticamente similar à obtida para sementes nuas $(86 \%)$ e que foi mais elevada do que sementes peletizadas com gesso (60\%) e com gesso e S. capricornutum (62\%). A melhor porcentagem de emergência para C. sorokiniana em comparação com S. capricornutum pode estar relacionada ao maior conteúdo de lipídios $\left(11,4 \mathrm{mgL}^{-1}\right)$ e carboidratos $\left(25,0 \mathrm{mg} \mathrm{L}^{-1}\right)$ em C. sorokiniana, em comparação com S. capricornutum $\left(2,2 \mathrm{mg} \mathrm{L}^{-1}\right.$ lipídios e $0,31 \mathrm{mg} \mathrm{L}^{-1}$ carboidratos). Parâmetros como tempo médio de emergência, comprimento e peso da parte aérea fresca e seca e radicular das plântulas de B. virgilioides foram similares para todos os tratamentos. Conclui-se que a biomassa de C. sorokiniana pode ter aplicação promissora como constituinte de material cimentante em peletização de sementes, apresentando resultados posistivos e similares à emergência de sementes nuas.
\end{abstract}

Palavras-chave: Sucupira do Cerrado; Chlorella sorokiniana; Selenastrum capricornutum.

\section{USE OF ALGAE BIOMASS FOR THE PELLETIZATION OF Bowdichia virgilioides Kunth SEEDS}

\begin{abstract}
Microalgae are considered promising organisms with applications in several areas, among them $\mathrm{CO}_{2}$ fixation, food industry, cosmetics and pharmaceuticals. Industrialization in the production of such organisms will generate algae residues that may be used for production cost reduction. In this research we proposed the use of microalgae as cement material in Bowdichia virgilioides Kunth seeds pelletization. This plant is a native species of the cerrado (Brazilian savanna). Microalgae biomass Selenastrum capricornutum and Chlorella sorokiniana were obtained from semi-controlled cultures kept in a greenhouse. In microalgae, the concentrations of chlorophyll a, proteins, carbohydrates and total lipidswere calculated, and pelletization biomass was obtained with the cells from stationary growth phase. As for the seeds, the treatments consisted of bare seeds, seed with agricultural gypsum, seed with agricultural gypsum and S. capricornutum or C. sorokiniana. Plant emergence and plantule development, as well as the presence of nitrogen fixing nodules
\end{abstract}

\footnotetext{
${ }^{1}$ Recebido em 25.01.2014 aceito para publicação em 07.08.2014.

${ }^{2}$ Programa de Pós Graduação em Ecologia e Recursos Naturais, Universidade Federal de São Carlos, SP, Brasil. E-mail: <gramontanhim@yahoo.com.br>.

${ }_{3}^{3}$ Departamento de Botânica, Universidade Federal de São Carlos, São Carlos, SP, Brasil. E-mail: <renatanathaneda@gmail.com>,

<lombardi@ufscar.br>e<ines@ufscar.br>.
} 
were quantified. The results showed that seeds with gypsum and $\mathbf{C}$. sorokiniana had $76 \%$ germination percentage, which was statistically similar to that obtained for bare seeds (86\%); these were higher than the seeds pelleted with gypsum (60\%) and gypsum plus $\boldsymbol{S}$. capricornutum (62\%). The best emergence percentage obtained for C. sorokiniana when compared with S. capricornutum may be related to the higher lipid content (11.4 $\mathrm{mg} \mathrm{L}^{-1}$ ) and carbohydrate content (25.0 mg L $\left.\mathrm{L}^{-1}\right)$ in C. sorokiniana, compared with S. capricornutum (2.2 $\mathrm{mg} \mathrm{L}^{-1} \mathrm{of}$ lipids and $0.31 \mathrm{mg} \mathrm{L}^{-1}$ of carbohydrate). Parameters such as mean emergence time, length and fresh and dry weight of aerial plants and roots of $\boldsymbol{B}$. virgilioides plantules were similar for all treatments. From this research it can be concluded that $\boldsymbol{C}$. sorokiniana biomass can have potential for application as a constituent of cement material in seed pelletization, presenting positive results that were similar to the emergence of bare seeds.

Keywords: Savanna sucupira; Chlorella sorokiniana; Selenastrum capricornutum.

\section{INTRODUÇÃO}

As algas são organismos utilizados na indústria alimentícia, cosmética e farmacêutica devido à gama de compostos que são capazes de sintetizar (BECKER, 2008). As microalgas produzem, além de biomoléculas como os lipídios, de grande interesse na indústria da bioenergia, carboidratos e proteínas. Tais compostos podem agregar valor à biomassa residual, aumentando as possibilidades de uso desse material, e, em se tratando de culturas de microalgas em larga escala, é esperada grande quantidade de resíduos. A reutilização desse material é necessária e ambientalmente importante, já que sua decomposição poderia emitir significativa quantidade de $\mathrm{CO}_{2}$ (LAGUNA, 2012).

Uma possível aplicação para a biomassa residual de microalgas é a peletização de sementes. Trata-se de um processo em que se faz o revestimento de sementes com camadas sucessivas e alternantes de um material cimentante solúvel em água com a aplicação do material de enchimento (SILVA; NAKAGAWA, 1998; ALMEIDA, 2004). Proporciona formato e massa adequados ao manuseio, facilitando o plantio, principalmente no que se refere a sementes extremamente pequenas, pilosas, ou deformadas (LOPES; NASCIMENTO, 2012). Lopes e Nascimento (2012) afirmaram ainda que, apesar de algumas indicações, qualquer semente pode ser peletizada, de acordo com o objetivo.

Entre as vantagens da utilização de sementes peletizadas, destacam-se a redução dos custos de produção de mudas, redução do trabalho manual de distribuição das sementes, incorporação de nutrientes e reguladores de crescimento durante a peletização (SILVA et al., 2002; LOPES; NASCIMENTO, 2012). Entretanto, apesar de as inúmeras vantagens das sementes peletizadas, elas podem apresentar atraso no tempo de germinação, menor emergência das plântulas, plântulas com aspectos atípicos em comparação com sementes não peletizadas (CORASPE et al., 1993; LOPES; NASCIMENTO, 2012) e dificuldade das trocas gasosas entre a semente e o ambiente externo (LOPES; NASCIMENTO, 2012). Há ainda a possibilidade de redução de vigor, como em sementes de tomate (PEREIRA et al., 2001).

Vários são os processos conhecidos e adotados para a peletização de sementes e, além do material cimentante, pode-se utilizar gesso agrícola, que influencia positivamente o enraizamento de plantas em solos profundos (AGRONELLI, 2011). A utilização de gesso agrícola é recomendada para solos do tipo dos de Cerrado (SOUSA et al., 2005).

Considerando que as microalgas possuem grande quantidade de material mucilaginoso higroscópico constituído, principalmente, de polissacarídios (LOMBARDI et al., 2002), proteínas e lipídios (BERTOLDI et al., 2008; CHIA et al., 2013; ROCHA et al., 2014), sua incorporação na peletização de sementes pode contribuir para o desenvolvimento das plantas. Também fornecem materiais orgânicos biodegradáveis ao solo, como ocorre com o biofertilizante produzido por algas marinhas - sobretudo do gênero Lithothamnium, chamado de granulado bioclástico (VASCONCELOS, 2012).

Na natureza, várias características dos vegetais e do clima podem interagir, dificultando a germinação da vegetação nativa. Bowdichia virgilioides ocorre em várias regiões do Brasil e é popularmente conhecida como sucupira-do-cerrado, ou sucupira-preta. Pode ser utilizada no paisagismo, além do aproveitamento da madeira na indústria moveleira (SILVAJÚNIOR, 2012). Segundo a Resolução da Secretaria do Meio Ambiente 48, de 21/09/2004, publicada no Diário Oficial do Estado de São Paulo em 22/06/2004, B. virgilioides apresenta redução acentuada no número populacional, devido à exploração comercial desordenada e dormência exógena, 
que diminui a porcentagem de germinação e a emergência. Assim, é considerada espécie ameaçada de extinção em categoria vulnerável, de acordo com a International Union for Conservation of Nature (IUCN).

Diante de tais informações, este trabalho buscou o uso de biomassa residual de Chlorella sorokiniana e Selenastrum capricornutum na peletização de Bowdichia virgilioides, a fim de favorecer seu poder germinativo e o crescimento inicial das plântulas.

\section{MATERIAL E MÉTODOS}

A biomassa de microalgas necessária para o processo de peletização das sementes foi obtida por meio do cultivo de duas espécies de algas clorofíceas: Selenastrum capricornutum Printz e Chlorella sorokiniana Shihira \& R.W. Krauss, e o critério de seleção dessas espécies foi a facilidade de cultivo em laboratório, o que as torna candidatas potenciais candidatas à produção em escalas ampliadas.

Para o estabelecimento das condições mais adequadas de crescimento das algas, foram feitos prétestes com as duas espécies. A taxa de crescimento mais elevada de S. capricornutum ocorreu em condições controladas de temperatura e luminosidade em laboratório, enquanto C. sorokiniana apresentou taxa de crescimento mais elevada em condições semicontroladas em casa de vegetação $\left(110\right.$ a $330 \mu \mathrm{mol} \mathrm{s}{ }^{-1} \mathrm{~m}^{-2}$ e 15 a $\left.45^{\circ} \mathrm{C}\right)$.

\subsection{Cultura de Selenastrum capricornutum Printz}

Uma alíquota de $300 \mathrm{~mL}$ contendo $10^{6}$ células $\mathrm{mL}^{-1}$ de Selenastrum capricornutum foi inoculada em biorreator contendo 3 L de meio de cultura L.C. Oligo modificado (AFNOR, 1980), a fim de obter uma concentração final de $10^{5}$ células $\mathrm{mL}^{-1}$. As concentrações de todas as soluções foram duplicadas e a concentração de bicarbonato de sódio, quadruplicada.

A cultura foi mantida sob intensidade luminosa (166 $\mu \mathrm{mol} \mathrm{s}^{-1} \mathrm{~m}^{-2}$, com fotoperíodo de $12 \mathrm{~h} / 12 \mathrm{~h}$ ) e temperatura externa $\left(23^{\circ} \mathrm{C}\right)$ constantes. O crescimento das algas foi acompanhado, diariamente, por meio da contagem de células (hemacitômetro do tipo FuchsRosenthal), concentração de clorofila a in vivo, através de um fluorímetro digital (Turner Designs, Model Trilogy - USA), pH(LOGEN SCIENTIFIC, LSXXX-HH, São Paulo, Brasil) e densidade óptica (a 570 e 684 nm, com um espectrofotômetro digital Femto, 800 XI, São Paulo, Brasil).
Atingida a concentração de $10^{6}$ células $\mathrm{mL}^{-1}$, as culturas foram diluídas para a concentração inicial com meio de cultura L. C. Oligo (AFNOR, 1980) modificado, para a preparação de $10 \mathrm{~L}$. O mesmo procedimento foi adotado até que fossem atingidos 20 L de cultura, sendo os mesmos parâmetros de avaliação utilizados diariamente. Em cada um dos três biorreatores foram colocados uma bomba de agitação e um aerador.

O experimento foi encerrado aos 33 dias de cultivo, quando a cultura se encontrava na fase estacionária. Após a decantação das células, o sobrenadante foi retirado e a densidade celular, aferida.

\subsection{Cultura de Chlorella sorokiniana Shihira \& R.W. Krauss}

Para a produção de biomassa experimental, a cultura foi mantida em casa de vegetação em condições semicontroladas (controle de temperatura promovido por sistema de refrigeração úmido e exaustores, com iluminação natural durante 10 dias).

Utilizou-se meio L. C. Oligo com as mesmas modificações descritas no subitem 2.1. A intensidade luminosa foi de $110 \mu \mathrm{mol} \mathrm{s}^{-1} \mathrm{~m}^{-2}$ às $8 \mathrm{~h}$ e um máximo de $330 \mu \mathrm{mol} \mathrm{s}^{-1} \mathrm{~m}^{-2}$ às $13 \mathrm{~h}$. Diariamente, o $\mathrm{pH}$ era ajustado para 6,0 com a adição de mistura $\mathrm{CO}_{2} / \mathrm{ar}$ $3 \%$, ar comprimido. Nessas culturas, fotobiorreatores planares híbridos de 200 L de capacidade com 180 $\mathrm{L}$ de meio foram utilizados. Foi usado um inóculo de 20 L cultivado em condições controladas de laboratório. A cultura foi iniciada com $10^{5}$ células $\mathrm{mL}^{-1}$ em fase exponencial de crescimento e monitorada diariamente, por meio da contagem de células (hemacitômetro do tipo câmara de Fuchs-Rosenthal), determinação da concentração de clorofila a in vivo (Turner Designs, Model Trilogy - USA), pH (Hanna Instruments, HI 8424, USA) e densidade óptica em 570 e 684 nm, usando-se um espectrofotômetro FEMTO, 800 XI, São Paulo, Brasil.

Após 10 dias de cultivo, o sobrenadante foi retirado após a decantação celular e a densidade celular, aferida.

\subsection{Análises bioquímicas}

Na determinação de proteínas intracelulares, utilizou-se a metodologia de Bradford (1976). Em carboidratos intracelulares, seguiu-se o método de

Revista Árvore, Viçosa-MG, v.38, n.5, p.867-877, 2014 
Liu et al. (1973), e lipídios totais foram extraídos de acordo com o método de Folch, descrito e modificado por Parrish (1999) e quantificado por cromatografia de camada fina com detector de ionização de chama, de acordo com TLC/FID - Iatroscan (PARRISH, 1999).

\subsection{Processo de peletização}

Para os testes de peletização, utilizou-se a espécie típica do Cerrado Bowdichia virgilioides Kunth.

A quebra de dormência das sementes de $B$. virgilioides foi feita segundo Smiderle e Sousa (2003). Esses autores recomendaram escarificação química com ácido sulfúrico concentrado por $5 \mathrm{~min}$. Após a escarificação, as sementes foram imersas em solução de hipoclorito (20\%) com uma gota de Tween 80 . Após passar por esses tratamentos, as sementes foram secas com papel-filtro esterilizado e armazenadas em câmara de germinação do tipo B.O.D. (TECNAL, TE-390) a $27^{\circ} \mathrm{C}$, por $24 \mathrm{~h}$, antes de serem peletizadas.

Para o aferimento da qualidade das sementes, foram medidos a porcentagem de germinação até que houvesse a estabilização germinativa (CRUZ et al., 2012), o teor de água (BRASIL, 2009) e a condutividade elétrica (LOEFFLER et al., 1988). A porcentagem de germinação de sementes nuas (sem pelete) em condições controladas laboratoriais $\left(27^{\circ} \mathrm{C}\right.$ e fotoperíodo de $12 \mathrm{~h} /$ $12 \mathrm{~h}$ em câmara de germinação) foi aferida simultaneamente com o experimento de sementes peletizadas.

Quatro tratamentos foram utilizados para a peletização de sementes.

a) Nuas (controle); b) acetato de polivinila (PVA) diluído a 8\% (CONCEIÇÃO; VIEIRA, 2008) com água e gesso agrícola com fungicida Cerconil® e inseticida Diazinon $\AA(0,01$ g e 0,025 g, respectivamente, para cada $5 \mathrm{~g}$ de gesso agrícola); c) PVA diluído a $8 \%$ com biomassa algal úmida de Selenastrum capricornutum, gesso agrícola, fungicida e inseticida; d) PVA diluído a $8 \%$ com biomassa algal úmida de Chlorella sorokiniana, gesso agrícola, fungicida e inseticida.
As sementes peletizadas tiveram a espessura medida com paquímetro digital. Em cada tratamento foram semeadas 100 sementes em substrato organoarenoso e areia fina (na proporção $3: 1$ ) a $1,5 \mathrm{~cm}$. O experimento foi mantido em casa de vegetação com distribuição aleatória. Foram realizadas seis regas ao dia, durante 5 min, através de um sistema de aspersão de microgotas. $\mathrm{O}$ experimento foi mantido sob luminosidade média de $960 \mu \mathrm{mol} \mathrm{s}^{-1} \mathrm{~m}^{-2}$ e temperatura média de $38^{\circ} \mathrm{C}$ (horário de leituras: 12-13 h). Diariamente, foi registrado o número de sementes emergentes até que esse número se mostrasse estável durante três dias consecutivos (totalizando 43 dias de leituras).

\subsection{Análises estatísticas}

A influência da presença de microalgas nos peletes sobre a emergência de $B$. virgilioides foi avaliada através da Análise de Regressão Logística (JACCARD, 2001) (software Systat 12). Para análise estatística de dados com valores contínuos, utilizou-se ANOVA para dados paramétricos e Kruskal-Wallis (softwares Past 3.0, R 2. 13.1 e Origin 8.5) para dados não paramétricos. O intervalo de confiança foi de $95 \%$.

Foram realizadas análises estatísticas das variáveis emergência das plântulas, comprimentos de parte aérea e radicular (medidos com paquímetro digital) e pesos das partes aérea e radicular ( $\mathrm{g}$ ) frescas e secas, além do número de nódulos de bactérias fixadoras de nitrogênio.

\section{RESULTADOS}

As microalgas Selenastrum capricornutum e Chlorella sorokiniana cresceram exponencialmente até o $2^{\circ}$ dia $\left(9,1 \times 10^{5}\right.$ células $\mathrm{mL}^{-1}$ e taxa de crescimento de $\left.0,76 \mathrm{dia}^{-1}\right)$ e $4^{\circ}$ dia $\left(3,2 \times 10^{6}\right.$ células $\mathrm{mL}^{-1}$ e taxa de crescimento $\left.0,99 \mathrm{dia}^{-1}\right)$, respectivamente. As culturas cresceram até o décimo dia (C. sorokiniana, com 1,6 x $10^{7}$ células $\mathrm{mL}^{-1}$ e $2,5 \times 10^{8}$ células $\mathrm{mL}^{-1}$ da biomassa úmida) e trigésimo terceiro dia ( $S$. capricornutum, com 2,6 $\times 10^{6}$ células $\mathrm{mL}^{-1}$ e $1,7 \times 10^{8}$ células $\mathrm{mL}^{-1}$ da biomassa úmida), quando se obteve a biomassa algal úmida pela retirada do sobrenadante (Tabela 1 ).

Tabela 1 - Composição bioquímica da biomassa algal utilizada no processo de peletização de sementes de B. virgilioides Table 1 - Biochemical composition of algae biomass used in the pelletization process of $\boldsymbol{B}$. virgilioides seeds.

\begin{tabular}{ccccc}
\hline Clorofila $a\left(\mathrm{mg} \mathrm{L}^{-1}\right)$ & Lipídios $\left(\mathrm{mg} \mathrm{L}^{-1}\right)$ & Carboidratos $\left(\mathrm{mg} \mathrm{L}^{-1}\right)$ & Proteínas $\left(\mathrm{mg} \mathrm{L}^{-1}\right)$ & Cultura \\
\hline 1,31 & 2,21 & 0,31 & 5,6 & S. capricornutum \\
1,64 & 11,4 & 25,0 & 9,8 & C. sorokiniana \\
\hline
\end{tabular}


O peso de 1.000 sementes foi de $39 \mathrm{~g}$, havendo 25.641 sementes $\mathrm{kg}^{-1}$. As médias dos valores de espessura $(\mathrm{mm})$ das sementes foram diferentes entre sementes nuas e com gesso e $S$. capricornutum ( $\mathrm{p}=0,042)$. Também, houve diferença entre sementes nuas e com gesso ( $p$ $=0,004)$ e entre sementes nuas e com gesso e Chlorella sorokiniana $(\mathrm{p}=0,018)$. As sementes peletizadas foram mais espessas (Tabela 2). As sementes apresentaram teor médio de água de $8,1 \%$.

As sementes apresentaram valor médio de condutividade elétrica inicial de $39,8 \mu \mathrm{S} \mathrm{cm}^{-1} \mathrm{~g}^{-1}$ e aos

Tabela 2 - Espessura ( $\mathrm{mm}$ ) das sementes de Bowdichia virgilioides.

Table 2 - Bowdichia virgilioides seeds thickness ( $\mathrm{mm}$ ).

\begin{tabular}{ccc}
\hline Tratamento & Espessura $(\mathrm{mm})$ & \\
\hline Nua & $2,54 \pm 0,199$ & $\mathrm{~b}$ \\
Gesso & $4,63 \pm 0,675$ & $\mathrm{a}$ \\
Gesso + Sc & $4,41 \pm 0,786$ & $\mathrm{a}$ \\
Gesso $+\mathrm{Cs}$ & $5,142 \pm 0,3112$ & $\mathrm{a}$ \\
\hline
\end{tabular}

a

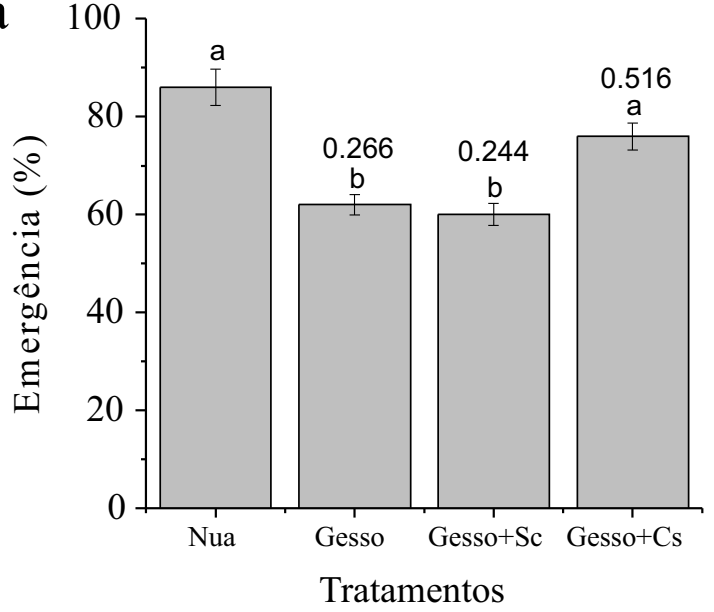

120 dias, de $52,5 \mu \mathrm{S} \mathrm{cm}^{-1} \mathrm{~g}^{-1}$, com diferença significativa $(\mathrm{p}=0,005)$.

O tratamento com gesso e Chlorella sorokiniana mostrou maior porcentagem de plântulas emergentes (76\%) em relação à porcentagem de plântulas oriundas do tratamento "gesso" $(62 \%)(\mathrm{p}=0,033)$. As sementes peletizadas com Selenastrum capricornutum apresentaram porcentual de germinação (60\%) estatisticamente igual ao de plântulas emergentes do tratamento "gesso".

Como esperado, os dados de densidade óptica e clorifila a in vivo corroboram os dados de densidade celular, pois as curvas são sobreponíveis.

Os experimentos indicaram que nas partes subterrâneas de B. virgilioides ocorreu o surgimento de nódulos fixadores de nitrogênio nas raízes de todos os tratamentos, correspondentes a $30 \%$ dos indivíduos, independentemente do tratamento. Isso confirma que a nodulação não foi prejudicada pelo processo de peletização com microalgas.

b

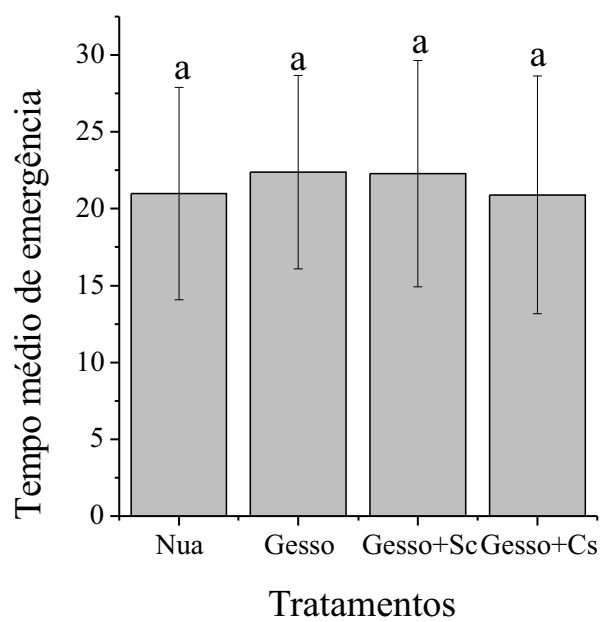

Figura 1 - a) Porcentagem; e b) tempo médio de emergência de plântulas oriundas de sementes peletizadas de Bowdichia virgilioides. Abreviação: Sc - Selenastrum capricornutum; e Cs - Chlorella sorokiniana. Letras diferentes significam diferenças entre tratamentos a $95 \%$ de confiança. Os valores descritos acima das barras no gráfico de porcentagem de emergência significam quantas vezes a probabilidade de emergência de plantas para o tratamento "sementes nuas" é maior do que a probabilidade para os demais tratamentos. Sementes nuas emergiram entre 31/12/2012 e 23/01/2013; Gesso: $1^{\circ}$ a 23/01/2013; Gesso + Sc: 02 a 26/01/2013; e Gesso + Cs: 02 a 24/01/2013.

Figure 1 - a) Percentage; and b) mean emergence time of plantules from Bowdichia virgilioides pelleted seeds. Abbreviations: Sc - Selenastrum capricornutum; and Cs - Chlorella sorokiniana. Different letters mean differences between treatments at 95\% confidence. The values described above the bars in the graph of emergence percentage mean how many times the probability of emergence of plants for the treatment "bare seeds" is greater than the probability for the other treatments. Bare seeds emerged between 31/12/2012 and 23/01/2013; Gypsum: 01 and 23/01/2013; Gypsum + Sc: 02 and 26/01/2013; and Gypsum + Cs: 02 and 24/01/2013. 

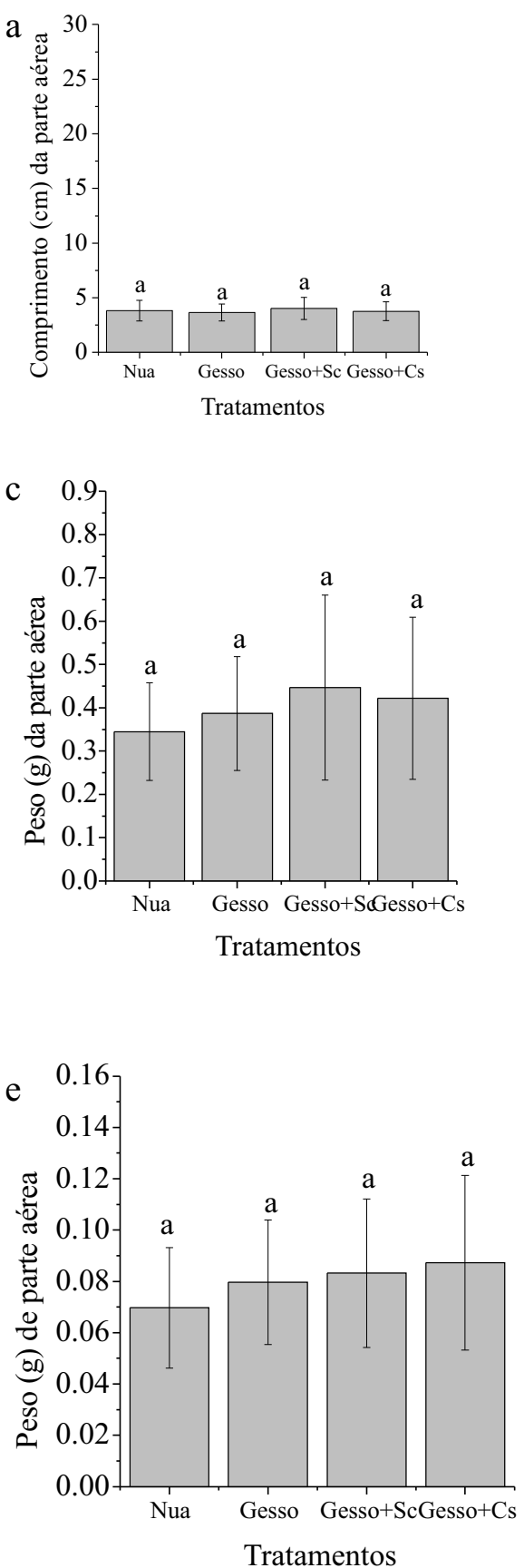
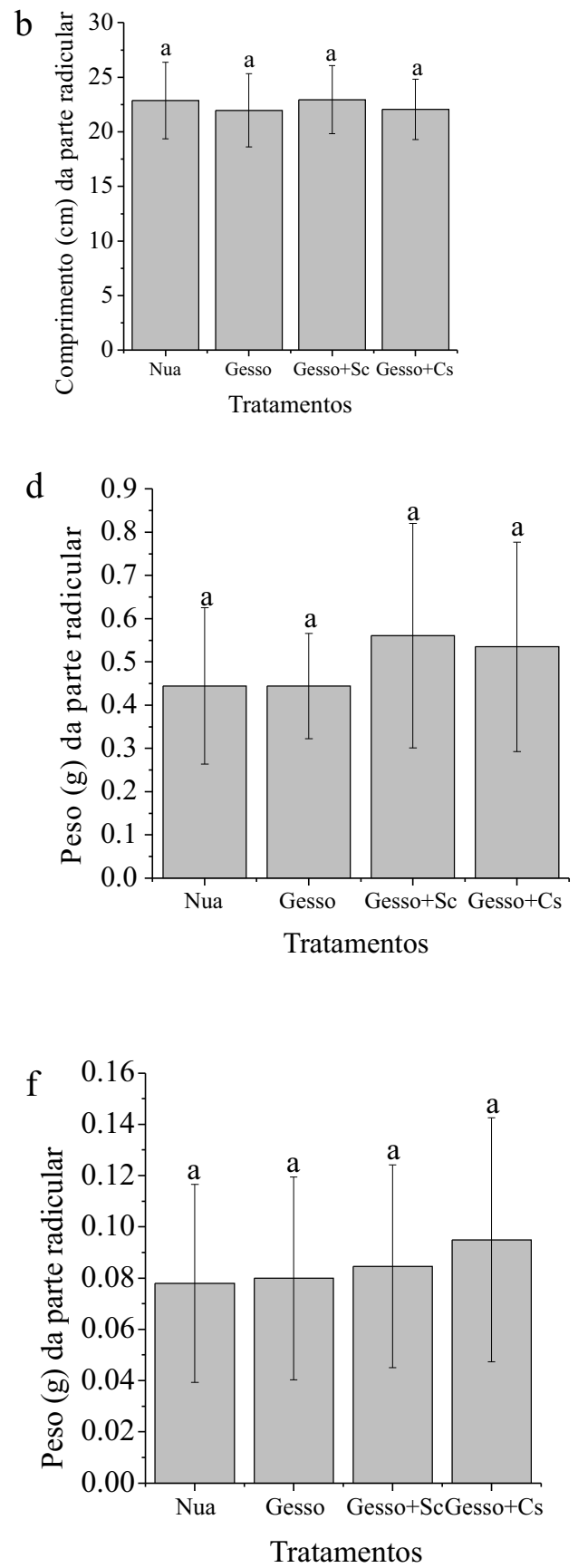

Figura 2 - Média dos valores de comprimento $(\mathrm{cm})$ da parte aérea (a) e da parte radicular (b); peso da parte aérea fresca (c) e peso da parte aérea seca (e); peso da parte radicular fresca (d); peso da parte radicular seca (f) de plântulas oriundas de sementes peletizadas de Bowdichia virgilioides. Abreviações: Sc: Selenastrum capricornutum; e Cs: Chlorella sorokiniana. Letras diferentes significam diferenças entre tratamentos a $95 \%$ de confiança.

Figure 2 - Mean values for length ( $\mathrm{cm}$ ) of shoot (a) and root (b); fresh weight of aerial part (c); weight of dry aerial part (e); weight of fresh root (d) weight of dry root ( $f$ ) plantules from Bowdichia virgilioides pelleted seeds. Abreviations: Sc - Selenastrum capricornutum; and Cs - Chlorella sorokiniana. Different letters mean differences between treatments at $95 \%$ confidence.

Revista Árvore, Viçosa-MG, v.38, n.5, p.867-877, 2014 
a
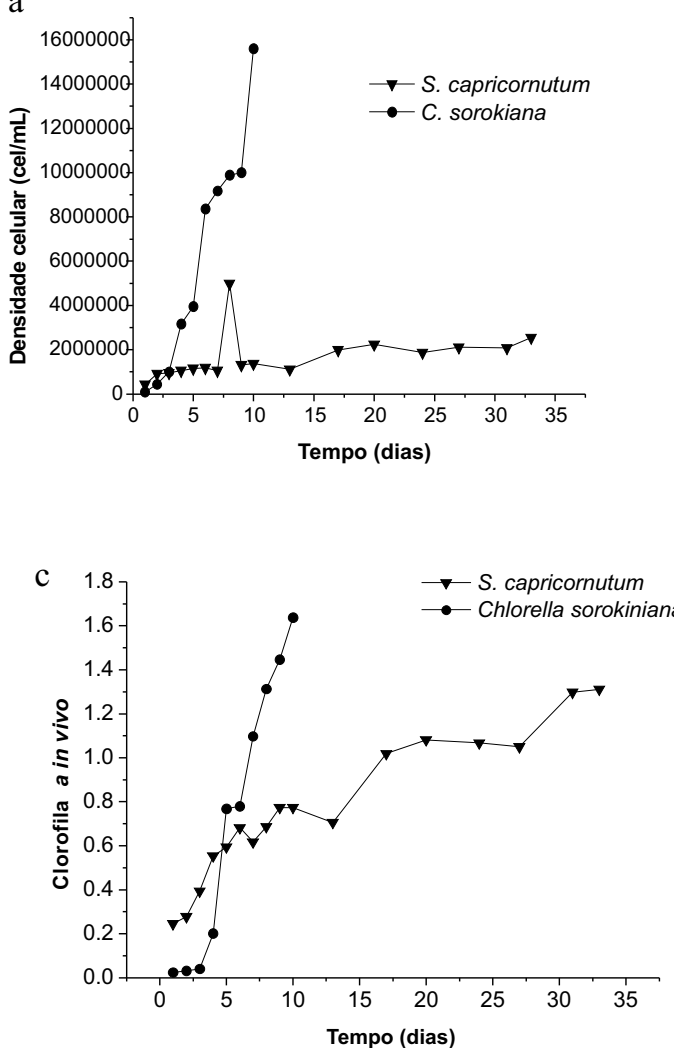

e

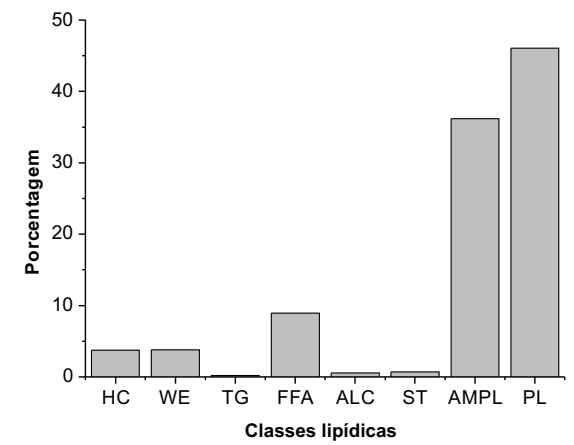

b

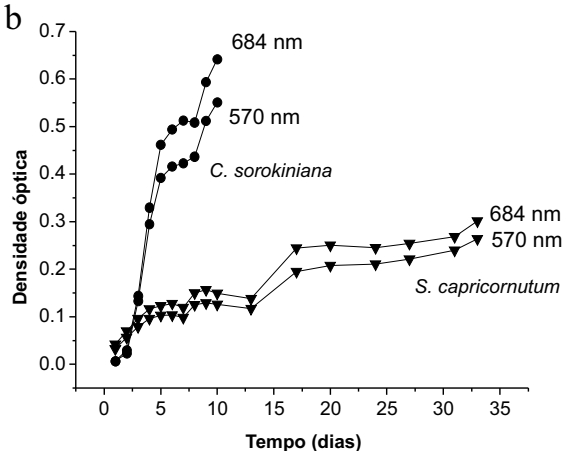

d

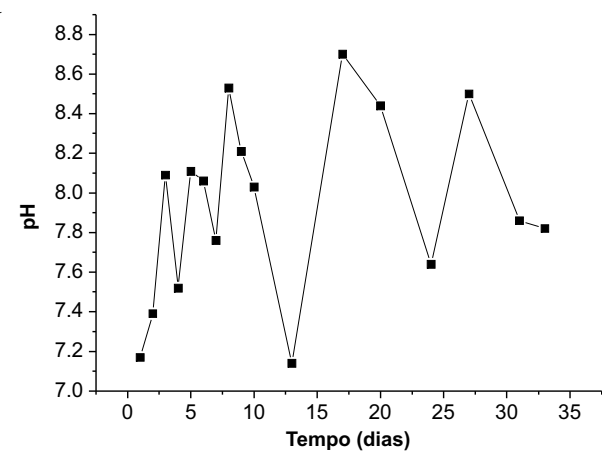

$\mathrm{f}$

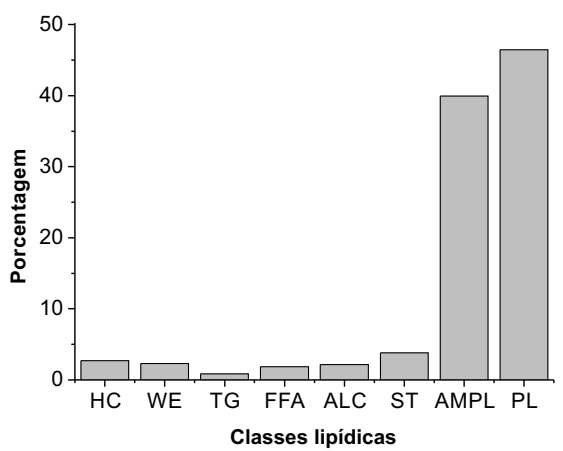

Figura 3 - a) Densidade celular média; b) densidade óptica (nm); c) clorofila $a$ em culturas de Selenastrum capricornutum e Chlorella sorokiniana; d) potencial hidrogeniônico da cultura de S. capricornutum; e) porcentagem das classes lipídicas de S. capricornutum; e f) porcentagem das classes lipídicas de C. sorokiniana. Abreviações: HC - hidrocarboneto alifático; WE - wax éster; TG - triacilglicerol; FFA - ácidos graxos livres; ALC - álcool alifático livre; ST - esterol livre; AMPL - acetone móbile polar lipids; e PL - fosfolipídios.

Figure 3-a) Average cell density; b) optical density (nm); c) chlorophyll a in Selenastrum capricornutum and Chlorella sorokiniana cultures; d) hydrogen potential of S. capricornutum culture; e) percentage of lipid classes of Selenastrum capricornutum; and f) percentage of lipid classes of C. sorokiniana. Abreviations: HC - aliphatic hydrocarbon; WE - wax ester; TG - triacylglycerol; FFA - free fatty acids; ALC - free aliphatic alcohol; ST - free sterol; AMPL - acetone mobile polar lipids; and PL - phospholipids. 


\section{DISCUSSÃO}

\subsection{Biomassa algal}

Os carboidratos e lipídios da biomassa das algas poderiam auxiliar o material cimentante do pelete, devido à presença de celulose na parede celular, a qual se une a outros polissacarídios e confere consistência gelatinosa (BARROSO, 2010), proporcionando aderência à semente. A biomassa de $S$. capricornutum conteve menor valor de carboidratos e lipídios totais (Tabela 1), em comparação com a biomassa de C. sorokiniana, e isso pode ter influenciado a menor porcentagem de emergência das sementes peletizadas com $S$. capricornutum. Além disso, a biomassa de $C$. sorokiniana continha concentração de lipídios totais cinco vezes maior do que a biomassa de $S$. capricornutum. Considerando que $B$. virgilioides pertence à família Fabaceae e que Ávila e Albrecht (2010) mostraram que a soja, outra leguminosa da família Fabaceae capaz de absorver nutrientes, proteínas e lipídios do meio externo, é provável que a diferença na germinação de $B$. virgilioides induzida pelos diferentes materiais cimentantes possa ser devida à diferença na composição bioquímica das microalgas, que teriam fornecido materiais nutritivos distintos a $B$. virgilioides.

A razão proteínas:carboidratos $(\mathrm{P}: \mathrm{C})$ diz respeito ao estado fisiológico e nutricional em culturas de microalgas (KILHAM et al., 1997; ZHAO et al., 2009). Em geral, valores maiores do que 2, que indicam 50\% mais proteínas em comparação com os carboidratos, indicam células saudáveis e que ainda não estocaram material de reserva, enquanto os lipídios e carboidratos são biomoléculas de reserva acumuladas em condições de estresse (ROCHA et al., 2014). Segundo esses autores, espera-se maior conteúdo de carboidratos em relação a proteínas em células em fase estacionária de crescimento. Os resultados desta pesquisa quanto à razão $\mathrm{P}: \mathrm{C}(0,4$ - C. sorokiniana; 18 - S. capricornutum) estão de acordo com os de Illman et al. (2000), que obtiveram razão $\mathrm{P}: \mathrm{C} \sim 0,5$ para $C$. vulgaris. Assim, pode-se inferir que proteínas totais não interferiram significativamente na emergência das plântulas, não interferindo, consequentemente, no processo de nodulação das raízes com bactérias fixadoras de nitrogênio.

A produção de carboidratos por C. sorokiniana foi maior do que a apresentada em Ho et al. (2012). Esses autores, investigando o crescimento e composição bioquímica de C. vulgaris, obtiveram $12,16 \%$ de carboidratos em relação à biomassa seca total da cepa, que possuía taxa de crescimento igual a 0,99 . Neste estudo, C. sorokiniana apresentou $35,71 \%$ de carboidratos em relação à biomassa total, e.g., $23 \%$ mais do que C. vulgaris. Entretanto, a taxa de crescimento obtida para C. sorokiniana nesta pesquisa foi igual à que Ho et al. (2012) obtiveram para C. vulgaris. O conteúdo de lipídios em relação à biomassa seca em C. sorokiniana (nesta pesquisa) e C. vulgaris (HO et al., 2012) foram similares, sendo $15,2 \%$ na primeira e $11,6 \%$ na segunda.

\subsection{Sementes de $B$. virgilioides}

No estudo realizado por Gonçalves et al. (2008), estudando sementes de $B$. virgilloides, eles encontraram $21,2 \mathrm{~g} \mathrm{em} 1.000$ sementes e 47.175 sementes $\mathrm{kg}^{-1}$. As diferenças entre o tamanho, o peso de 1.000 sementes e o número de sementes $\mathrm{kg}^{-1}$ encontradas entre os dados deste trabalho e os da literatura citada podem ser explicadas pelas variações genéticas e ambientais entre as populações (BIANCHETTI, 1991; AZEREDO et al., 2003).

Neste trabalho, o valor médio de porcentagem de germinação de sementes de $B$. virgilioides em condições laboratoriais de $79 \%$ e de $86 \%$ em casa de vegetação foram inferiores aos obtidos em Smiderle e Sousa (2003), que obtiveram $90 \%$ de germinação de sementes escarificadas com ácido sulfúrico durante 5 min e mantidas em câmara de germinação a $25^{\circ} \mathrm{C}$ (SMIDERLE; SOUSA, 2003).

De acordo com as Regras de Análises de Sementes (BRASIL, 2009), o valor de $8,1 \%$ obtido neste trabalho é considerado adequado para o armazenamento de sementes e desenvolvimento de experimentos, já que o valor máximo de tolerância $(0,5 \%)$ não foi atingido. Valor similar $(9,1 \%)$ foi encontrado por Gonçalves et al. (2008) para umidade das sementes.

Os resultados desta pesquisa indicaram que biomassa de microalgas apresenta potencial para uso em peletização de sementes. Comparando os resultados deste estudo, observou-se que o tratamento com gesso e C. sorokiniana resultou em porcentagem de emergência similar ao controle, porém maior do que o tratamento com $S$. capricornutum $(\mathrm{p}<0,05)$. Esses resultados estão em concordância parcial com os apresentados por Lopes e Nascimento (2012), que obtiveram menor taxa de emergência em comparação 
com sementes nuas (controle). Observou-se efeito negativo do gesso, que foi suplantado pela peletização com C. sorokiniana, mas não com S. capricornutum.

Pradella et al. (1989) estudaram a viabilidade da peletização de sementes com alginato de sódio geleificado em solução de cloreto de cálcio em sementes de espécies nativas da Serra do Mar. Esses autores indicaram que a peletização assegurou condições propícias para a germinação e posterior desenvolvimento das plântulas no solo. Os resultados diferiram do apresentado em Pradella et al. (1989), pois não se obteve diferença significativa em comparação com o controle de qualquer um dos tratamentos quanto ao comprimento da parte aérea ou radicular e tampouco quanto à biomassa vegetal resultante da germinação das sementes peletizadas.

Diferentemente dos resultados apresentados neste estudo, Silva et al. (2002) não obtiveram diferença significativa entre o controle e germinação de sementes peletizadas. Esses autores observaram que todas as formulações utilizadas na peletização causaram redução na velocidade de germinação em ambiente natural, mas, segundo eles, resultados promissores foram obtidos em condições parcialmente controladas de casa de vegetação.

Reforça-se o caráter positivo da introdução de C. sorokiniana no material peletizante, pois, além de não interferir na emergência das plântulas, o resultado da peletização com essa microalga suplantou os aspectos negativos do gesso. Observou-se que o caráter promissor dessa peletização se alia à possibilidade de agregar substâncias protetoras das sementes, como fungicidas e inseticidas, ao gesso e à microalga. Isso teria por finalidade proteger as sementes, permitindo a sua melhor conservação no solo.

\section{CONCLUSÕES}

Esta pesquisa indicou que sementes de $B$. virgiliodes peletizadas com gesso acrescido de biomassa residual da microalga clorofícea Chlorella sorokiniana ocasionaram melhoria na germinação das sementes, igualando-se às sementes nuas e suplantando o efeito negativo provocado pelo gesso. Entretanto, não se observou efeito positivo ou negativo sobre parâmetros de avaliação da biomassa de $B$. virgilioides após a germinação e nem sobre o comprimento das plântulas.

\section{REFERÊNCIAS}

\section{ASSOCIATION FRANÇAISE DE} NORMALISATION - AFNOR. Essais des eaux. Determination de línhibition de Scenedesmus subspicatus par une substance. Norme experimentale T90-304. 1980.

AGRONELLI. Insumos agrícolas. 2011. Disponível em: http:// www.agronelliagricola.com.br/ Acesso em 21 de setembro de 2011.

\section{ALMEIDA, N. O. Implantação de matas ciliares por plantio direto utilizando- se sementes peletizadas. 2004. 269f. Tese (Doutorado em Ciências Florestais) - \\ Universidade Federal de Lavras, Lavras, 2004.}

ÁVILA, M.R.; ALBRECHT, L.P. Isoflavonas e a qualidade das sementes de soja. Informativo Abrates, v.20, p.15-29, 2010.

AZEREDO, G. A. et al. Germinação em sementes de espécies florestais da Mata Atlântica (Leguminoseae) sob condições de casa de vegetação. Pesquisa Agropecuária Tropical, v.33, n.1, p.11-16, 2003.

\section{BARROSO, E. Procariontes e protistas}

fotossintetizantes. 2010.Universidade Estadual do Maranhão. Departamento de Química e Biologia. Disponível em: http://pt.scribd.com/doc/88000102/ ALGASPROTISTAS Acesso em 02 de abr. de 2013.

BECKER, E. W. Microalgae: biotechnology and microbiology. New York: Cambridge University Press, 2008. 293p.

BERTOLDI, F. C. et al. Revisão: biotecnologia de microalgas. Boletim Centro de Pesquisa de Processamento de Alimentos, v.26, n.1, p.9-20, 2008.

BIANCHETTI, A. Tratamentos pré-germinativos para sementes florestais. In: SIMPÓSIO BRASILEIRO SOBRE SEMENTES FLORESTAIS, 2., 1989, Atibaia. Anais... São Paulo: Instituto Florestal, 1991. p.237-246.

BRADFORD, M. M. A rapid and sensitive method for the quantitation of microgram quantities of protein utilizing the principle of protein-dye binding. Analytical Biochemistry, v.72, n.1, p.248-254, 1976.

Revista Árvore, Viçosa-MG, v.38, n.5, p.867-877, 2014 
BRASIL. Ministério da Agricultura e Reforma Agrária. Regras para análise de sementes. Brasília, DF: SNDA/DNDV/CLAV, 2009. 398p.

CHIA, A. M. et al. Lipid composition of Chlorella vulgaris (Trebouxiophyceae) as a function of different cadmium and phosphate concentrations. Aquatic Toxicology, v.128, p.171-182, 2013 .

CONCEIÇÃO, P. M.; VIEIRA, H. D. Qualidade fisiológica e resistência do recobrimento de sementes de milho. Revista Brasileira de Sementes, v.30, n.3, p.48-53, 2008.

CORASPE, H. M. et al. Avaliação do efeito da peletização sobre o vigor de sementes de alface (Lactuca sativa L.). Scientia Agricola, v.50, n.3, p.349-354, 1993.

CRUZ, A. F. et al. Métodos para análise de sementes de Bowdichia virgilioides Kunth. Scientia Forestalis, v.40, n.93, p.77-84, 2012.

GONÇALVES, J. V. F. et al. Caracterização física e avaliação da pré-embebição na germinação de semetes de sucupira-preta (Bowdichia virgilioides KUNTH). Revista Cerne, v.14, n.4, p.330-334, 2008.

HO, S. H. et al. Characterization and optimization of carbohydrate production from an indigenous microalga Chlorella vulgaris FSP-E. Bioresource Technology, 2012. http:// dx.doi.org/10.1016/j.biortech.2012.10.100.

IILLMAN, A. M. et al. Increase in Chlorella strains calorific values when grown in low nitrogen medium. Enzyme Microbial Technology, v.27, p.631-635, 2000.

JACCARD, J. Interaction effects in logistic regression. Sage university papers series on quantitative application in the social sciences. Thousand Oaks, 2001.70p.

KILHAM, S. et al. Effects of nutrient limitation on biochemical constituents of Ankistrodesmus falcatus. Freshwater Biolology, v. 38 , p.591-596, 1997.
LAGUNA, V. G. Chuvas provocam aumento de algas na piscina, contaminando a água e a saúde do usuário. Sibrape, News, 2012. Disponível em: http://www.sibrape.com.br/news Acessado em 02 de abr. de 2013.

LOEFFLER, T. M. et al. The bulk conductivity test as an indicator of soybean seed quality. Journal of Seed Technology, v.12, n.1, p. 37-53, 1988 .

LOMBARDI, A. T. et al. Mucilaginous capsule adsorption and intracellular uptake of copper by Kirchneriella aperta. Journal of Phycology, v. 38, p.332-337, 2002.

LOPES, A.C.A.; NASCIMENTO, W.M. Peletização em sementes hortaliças. Brasília: Embrapa Hortaliças, 2012. 28p. (Documentos, 137)

LIU, D. et al. Determination of carbohydrate in lake sediment by a modified phenolsulfuric acid method. Water Research, v.7, p.741-746, 1973 .

PARRISH, C. C. Determination of total lipid, lipid classes, and fatty acids in aquatic samples. In: WAINMAN, B. C. (Ed.). Lipids in freshwater ecosystems. New York: Springer-Verlag: M. T. Arts, 1999. p.4-20.

PEREIRA, C. E. et al. Desempenho de sementes de tomate revestidas com diferentes materiais. Horticultura Brasileira, v.19, n.2, p.286, 2001.

PRADELLA, D. Z. A. et al. Peletização de sementes em gel hidrofílico. Revista Brasileira de Sementes, v.11, n.1, p.43$52,1989$.

ROCHA, G. S. et al. Growing Scenedesmus quadricauda in used culture media: is it viable? Journal Applied Phycology, 2014. DOI 10.1007/s10811-014-0320-8

SILVA, J. B. C.; NAKAGAWA, J. Confecção e avaliação de péletes de sementes de alface, Horticultura Brasileira, v. 16, n.2, p.151-158, 1998. 
SILVA, J. B. C. et al. Desempenho de sementes peletizadas de alface em função do material cimentante e da temperatura de secagem dos péletes. Horticultura Brasileira, v.20, n.1, p.67-70, 2002.

SILVA JÚNIOR, M. C. 100 árvores do cerrado - sentido restrito. Brasília: Rede de Sementes do Cerrado, 2012. 304p.

SMIDERLE, O. J.; SOUZA, R. C. P. Dormência em sementes de paricarana (Bowdichia virgilioides Kunth - Fabaceae - papilionidae). Revista Brasileira de Sementes, v.25, n.1, p.72-75, 2003.
SOUSA, D. M. G. et al. Uso de gesso agrícola nos solos do cerrado. Planaltina: Embrapa Cerrados, 2005. 18p. (Circular Técnica, 32)

VASCONCELOS, Y. Fertilizante marinho. Uso de algas calcárias como adubo em lavouras de cana pode elevar a produtividade em até $50 \%$. Revista Pesquisa FAPESP, v.197, p.62-65, 2012.

ZHAO, Y. F. et al. Biochemical compositions of two dominant bloom-forming species isolated from the Yangtze River Estuary in response to different nutrient conditions. Journal of

Experimental Marine Biology and Ecology, v.368, p.30-36, 2009. 
